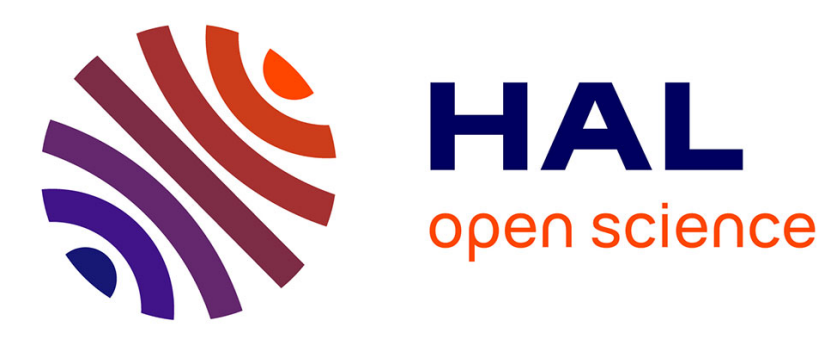

\title{
Does public housing occupancy increase unemployment?
}

Claire Dujardin, Florence Goffette-Nagot

\section{To cite this version:}

Claire Dujardin, Florence Goffette-Nagot. Does public housing occupancy increase unemployment?. Journal of Economic Geography, 2009, 9, pp. 823-851. 10.1093/jeg/lbp002 . halshs-00436679

\section{HAL Id: halshs-00436679 \\ https://shs.hal.science/halshs-00436679}

Submitted on 27 Nov 2009

HAL is a multi-disciplinary open access archive for the deposit and dissemination of scientific research documents, whether they are published or not. The documents may come from teaching and research institutions in France or abroad, or from public or private research centers.
L'archive ouverte pluridisciplinaire HAL, est destinée au dépôt et à la diffusion de documents scientifiques de niveau recherche, publiés ou non, émanant des établissements d'enseignement et de recherche français ou étrangers, des laboratoires publics ou privés. 


\title{
Does public housing occupancy
}

\author{
increase unemployment? *
}

\author{
Claire Dujardin \\ Université catholique de Louvain - F.R.S.-FNRS † \\ Florence Goffette-Nagot \\ Université de Lyon, CNRS, GATE ${ }^{\ddagger}$
}

November 2008

\begin{abstract}
This paper shows that living in public housing has no effect on the probability of being unemployed in France, once we account for the endogeneity of public housing. We estimate a simultaneous probit model of unemployment and public housing. On a first sample for Lyon, we instrument public housing with the gender composition of children. On a second national sample, the instrument is the city-level share of public housing. Both samples yield the same

*Claire Dujardin thanks the F.R.S.-FNRS for financing a research stay at GATE. Florence Goffette-Nagot acknowledges funding from the MiRe (Ministère de 1 Emploi, de la Cohésion sociale et du Logement and Ministère de la Santé et des Solidarités). Census data from the French National Institute for Statistics (Insee) was provided by the Centre Maurice Halbwachs. The authors gratefully thank the Division Logement (Insee) for the agreement Insee/Gate/Inra that allowed using data from the French Housing Survey.

${ }^{\dagger}$ Université catholique de Louvain, CORE, Voie du Roman Pays, 34, B-1348 Louvain-la-Neuve, Belgium. Email: claire.dujardin@uclouvain.be.

${ }^{\ddagger}$ Université de Lyon, Lyon, F-69003, France; CNRS, GATE, UMR 5824, Ecully, F-69130, France. Email: goffette-nagot@gate.cnrs.fr. Corresponding author.
\end{abstract}


conclusion, which we justify by showing that a small amount of selection on unobservables is enough to eliminate the positive effect found in "naive" estimates.

Keywords: Public housing, unemployment, simultaneous probit models, instrumental variables.

JEL code: R2, J64. 


\section{Introduction}

Recent urban economic models have formalized the relationships between the housing market and the labor market. This literature demonstrates that if job search efficiency decreases with distance to employment and if search intensity is endogenous, then a spatial mismatch can emerge, because a fraction of the unemployed choose to stay far away from employment and to search less intensively (Smith and Zenou, 2003; Wasmer and Zenou, 2006). These individuals locate in the city periphery, where they benefit from lower housing prices but experience longer unemployment spells.

These mechanisms can also apply to public housing. Indeed, the concentration of lowincome and unemployed people in public housing is likely to decrease their access to information on job opportunities. The literature on social networks and unemployment gives convincing arguments supporting the idea that access to employment is strongly influenced by the share of employed people in a person's environment (Granovetter, 1995; Reingold, 1999). As a consequence, one may think that public housing renters may ceteris paribus suffer higher unemployment probabilities because they have lower arrival rates of job opportunities, they search less intensively, but they stay in this situation because they benefit from lower housing prices.

There is another rationale in favor of a harmful effect of public housing on unemployment. The literature on the effects of tenure on labor-market outcomes argues that due to lower mobility rates, homeowners are more likely to suffer longer unemployment spells. Due to waiting lists for access to another public housing unit, mobility rates of public housing tenants are lower than that of tenants in the private market and might then, following the same mechanisms as for homeowners, end up with higher unemployment probabilities (Battu et al, 2008).

It is therefore legitimate to test for the effect of public housing occupancy on unemployment. The French case seems particularly suitable for such a study, in particular because the 
public housing sector represents in France as much as $17 \%$ of the housing stock, and even $22 \%$ in cities above 50,000 inhabitants. The annual mobility rate of tenants is $10 \%$ in the public renting sector against $16 \%$ in the private renting sector (Debrand and Taffin, 2005), which is a consequence of a shortage of available housing units with respect to the number of applicants: once in the public housing sector, households have incentives to stay in it because moving means incurring the risk of not having another public housing unit. Moreover, $12 \%$ of individuals above 18 in the public housing sector are unemployed against $5 \%$ for people in other tenures, which probably affects the access to information on job opportunities of all public housing tenants. As a consequence, one may wonder whether public housing might act as a poverty trap by decreasing residential mobility and access to employment in French cities.

This question is of importance from a public policy viewpoint. Two main policies are used in order to improve housing consumption in France as in other countries: housing vouchers and public housing. It has been shown empirically that housing vouchers largely result in housing price increases which lower their efficiency (Fack, 2006). The public housing sector escapes this shortcoming but may generate other externalities. This paper intends at sheding some light on the externalities that may affect unemployment. The literature on this matter is scarce up to now. Analyses of the effect of public housing on unemployment were carried out by some authors, for example Battu et al (2008) and Flatau et al (2003). Our analysis differs from these two papers as discussed below. Furthermore, we are not aware of any such study in the French case. ${ }^{1}$

A key issue in the literature on the relationship between housing tenure and labor market outcomes is the endogeneity of tenure and the identification of its causal effect. Endogeneity arises because the choice of housing tenure is correlated with labor-market outcomes. First and foremost, unemployment is likely to reduce the household's income and to increase the proba-

\footnotetext{
${ }^{1} \mathrm{~A}$ recent exception is De Graaf et al (2009) who study tenure effects on the labour-market in 14 European countries, including France.
} 
bility to live in the public housing sector. Second, it can be shown that individuals with a low attachment to the labor-market might search less intensively for a job and prefer to live in lowrent housing. Finally, public housing agencies might have criteria according to the household's economic situation and give preferential attribution to households with an unemployed adult. Failure to take endogeneity of tenure into account may yield biased estimates of the effect of tenure on labor-market outcomes.

In this paper, we estimate a simultaneous probit model of unemployment and public housing occupancy with public housing as an endogenous regressor in the unemployment equation. The effect of public housing is then identified by a careful choice of exclusions on two different samples. Firstly, we use a large sample of households living in Lyon (the second biggest French city) and we take advantage of demographic characteristics that influence attribution of public housing units. In particular, we use the gender composition of children, that determines the final number of children, as a shifter of public housing occupancy. Secondly, we use the French National Housing Survey which gives a nation-wide sample of households living in 102 different cities characterized by different situations on the housing market. In this sample, we identify the effect of public housing through the variation in the rate of public housing accross cities. This kind of identification is similar to the one used by Cutler and Glaeser (1997) to identify the effect of segregation on labor-market outcomes of minorities in the U.S. and by van Leuvensteijn and Koning (2004) to identify the effect of homeownership on job duration.

While descriptive statistics and 'naive' probit estimates suggest that public housing occupancy increases unemployment probability, correcting for the endogeneity of tenure allows us to rule out any detrimental impact of public housing on unemployment. This result is obtained for two different dataset and with different instruments. In particular, the gender composition of children is a valid instrument which allows us to show that the absence of effect of public housing on unemployment can not be rejected. Moreover, we perform a robustness check that 
consists in measuring the amount of correlation between unobservables that would be sufficient to explain the whole effect of public housing on unemployment. As the corresponding level of correlation is rather low, we conclude that this check reinforce our central result of no effect of public housing occupancy on unemployment.

The paper proceeds with Section 2 which presents the existing literature and public housing in France. Section 3 specifies the econometric model, the identification strategy and the data. Section 4 gives descriptive statistics and discusses the identification issue. Results and a robustness check are presented in Section 5 and Section 6 concludes.

\section{Background}

\subsection{Literature on tenure, public housing and outcomes}

Public housing is intended to provide a secured, decent and affordable housing for low-income households (which would otherwise occupy housing units of very poor quality). This purpose is supported by the idea that housing carries several positive externalities, as for instance externalities affecting children depending on the quality of the housing unit. For instance, Currie and Yelowitz (2000) study the impact of public housing occupancy on children educational outcomes in the U.S. and find empirical evidence that living in public housing projects actually improve living conditions and children educational outcomes. Similar results are found by Jacob (2004) and Newman and Harkness (2002) who find with U.S. data that public housing enhances children's educational and later employment outcomes.

Still, public housing can generate other kind of externalities that could be detrimental for public housing tenants. In the particular context of labor-market outcomes, several mechanisms support the idea that public housing occupants may have lower employment levels and experience longer spells of unemployment. The first group of mechanisms suggests that renters in the public 
sector have a poorer access to information on job opportunities. Indeed, public housing units are often located far from job locations, and as information on job opportunities decreases with distance to employment, the efficiency of their job search effort decreases (Ihlanfeldt, 1997). Similarly, the concentration of low-income and unemployed workers in public housing decreases the quality of social networks, which are known to be important in finding a job (Granovetter, 1995; Reingold, 1999). A second mechanism refers to the lower mobility rates of public housing tenants compared to other tenures. This is in line with the work of Oswald (1996) on the effect of homeownership on labor-market outcomes: homeowners facing higher transaction costs associated with a residential move (costs of buying and selling home) than private renters, they are less inclined to move residence to accept a job offer and they might thus stay longer unemployed. This mechanisms also apply to public housing renters. Indeed, because they have obtained the right to occupy a housing unit at a rent below market rates and because this right is not transferrable across municipalities or regions (owing to long waiting lists), social renters have lower residential mobility rates than private renters (see for instance Hughes and McCormick (1987) in the U.K.).

An important issue in the estimation of the effect of tenure on the labor-market outcomes is the endogeneity of tenure, which compromises the identification of a causal relationship. Several strategies have been used to control for the endogeneity of tenure. First, when a longitudinal data is used, it is possible to identify the effect of tenure on unemployment duration using multiple spells of unemployment for a given respondent, when tenure type varies over these spells (de Graaf et al, 2008; Battu et al, 2008; Munch et al, 2006 and 2008). A more traditional approach consists in using instrumental variables, i.e. variables influencing housing tenure but not correlated with labor-market outcomes. Two types of instruments are commonly used: aggregate-level instruments (such as the regional share of homeowners as in Leuvensteijn and Koning, 2004), or individual-level instruments (e.g. homeownership of parents as in Munch et al, 2008). 
To our knowledge, only a few analyses have studied the influence of public housing on labor-market outcomes. Svarer et al (2005) study the effect of rent control in Denmark (a different but related topic) and find that the probability of finding a job outside the local labor market is lower for individuals occupying housing units with high levels of rent control. However, these authors do not control for the endogeneity of tenure. Flatau et al (2003) find that public housing renters in Australia are more likely than private renters to be unemployed and that they remain longer unemployed, but the effect of public renting on unemployment disappears when controlling for the endogeneity of tenure. Finally, in a recent paper, Battu et al (2008) use longitudinal data and a multiple-spells strategy to correct for tenure endogeneity and find that public renters in the U.K. are more likely to stay unemployed compared to private renters and that they are less likely to leave unemployment for a distant job. Their results also reveal important differences whether one controls for the endogeneity of tenure or not.

\subsection{Public housing in France}

In France, almost one housing unit out of five is in the public housing sector. A large share of existing public housing units was built during the 60 's and the 70 's as a response to a serious shortage of housing following World War II. Rents in the public sector are administratively ruled. They are on average $50 \%$ below the market rent.

Although the public housing sector accounts for $17 \%$ of the French housing stock, eligible households (those meeting an income ceiling criteria) represent as much as two thirds of the population. Therefore, demand for public housing accommodation largely exceeds available housing units and there are long waiting lists for public housing applicants. Consequently, $31 \%$ of households who got access to public housing had to wait more than one year between their application and entry into a public housing unit; $13 \%$ waited for more than three years. ${ }^{2}$

\footnotetext{
${ }^{2}$ These figures as well as the following in this section are for couple households in city with more than 50,000 people, accordingly to our estimation sample definition (see Section 3.3).
} 
Waiting lists for access to public housing are also explained by the inertia of households in public housing. Indeed, $60 \%$ of public housing tenants have been occupying their dwelling for at least 4 years and $34 \%$ for at least 8 years (against $46 \%$ and $20 \%$ for tenants in the private market). This inertia, jointly with the large definition of public housing potential beneficiaries, explains that the economic situation of public housing tenants, although poor on average, is also varied: according to the 2002 French Housing Survey, 20\% of public housing renters belong to the four highest deciles of the income distribution (Jacquot, 2007).

Due to the long waiting lists, local public housing agencies have to rank applicants subject to several criteria pertaining not only to the economic situation, but also to the demographic situation. For instance, public housing agencies give priority to single-parent families, couples with young children and large families.

\section{Method}

Our empirical model is intended to test for the effect of public housing accommodation on unemployment. Tenure type is endogenous to employment status because unobserved individual characteristics that influence tenure choices are also likely to influence labor-market outcomes and reciprocally. As explained previously, some authors used multiple-spells estimation to overcome this problem. We argue however that this is not a satisfying option in our case. Indeed, using a multiple-spell identification supposes to observe a significant part of the sample in different situations, both in terms of housing and labor market. As explained in the previous section, public housing tenants have long spells in their housing. It is thus not clear whether identifying the effect of public housing through multiple spells would be possible.

This is the reason why, in this paper, we deal with the endogeneity of public housing accommodation by means of a simultaneous probit model of unemployment and public housing 
occupancy. As it deals with the correlation between unobservables in both equations, simultaneous probit model is a standard econometric method to correct for the endogeneity issue (Greene, 1998). Identification of public housing effects then relies on a set of instruments. We have two different datasets that will enable us to use two different types of instruments. In a first step, we resort to Population Census data for a single urban unit (Lyon) that enables us to use the gender composition of children as an instrument for public housing occupancy. Then, we use data from the French Housing Survey to estimate our model on a sample of households living in 102 different cities. This allows us to use the percentage of public housing units in the urban unit as an instrument. In this section, we present the empirical model (Section 3.1). We then motivate our choice of instruments (Section 3.2) and present our two datasets (Section 3.3). The choice of instruments will be assessed further in Section 4 .

\subsection{Empirical model and econometric method}

To estimate jointly unemployment probability and public housing occupancy, we have to deal with an individual-level equation for unemployment and an equation related to the residential situation, which supposes to estimate an household-level relationship. We only deal with couple households, because the case of single adults suffers from a selection bias, young adults being less likely to form a separate household if they are unemployed. Moreover, because dealing with women would imply to explain not only unemployment, but also labor-market participation, our study only concerns male household heads.

Although the classical theory of job search ends up in the estimation of unemployment duration models, the two datasets we use only allow us to estimate the probability of unemployment. This reduced form is assumed to represent both how local conditions affect the arrival rate of job offers and how they impact reservation wages. Unemployment is then explained, in a classical manner, by individual characteristics relative to experience (that will be proxied by 
age and its square to allow for a non-linear effect), education and previous occupation, because unemployment rates vary with skill level and professional status. The individual's nationality is included in order to account for potential discrimination by employers. It is also supposed to influence, in conjunction with the spouse's nationality, the access to information on job opportunities through the network of relatives. It is also worth noting that, because the spouse educational level might be suspected to influence the individual's participation on the labor market, it is included in the unemployment equation. In our accross-city sample, we also consider the average unemployment rate at the city level as a driver of individual unemployment probability. Finally, public housing accommodation is included as an explanatory variable of unemployment in order to test for our central hypothesis.

Accommodation in the public housing sector reflects both that the individual applied for, obtained and is still in a public housing unit at the observation date. It is supposed to be determined in the first place by the household's income. This income will be proxied by occupational status in previous job, educational level of the individual and his spouse, and age. Further, there is some evidence that individuals of foreign origin are discriminated against on the private renting market and are therefore more likely to resort to the public sector. Consequently, dummies for the individual's and his spouse's nationality are introduced in the public housing equation.

As our simultaneous probit model includes an endogenous observed discrete variable on its right hand side (public housing in the unemployment equation), it amounts to a mixed model. This kind of simultaneous model requires a coherency condition, which imposes a triangular form (Maddala, 1983; Blundell and Smith, 1994). That is, the observed variable of unemployment can not be introduced in the public housing equation. Of course, unemployment is likely to affect entry in the public housing sector and to prevent households from leaving it. To account for these influences while satisfying the coherency condition, we are restricted to include all the 
exogenous variables influencing unemployment in the public housing equation. In doing so, we account for the effect of observable characteristics determining unemployment probability on the residential situation. We still have to take into account unobservables influencing unemployment, and therefore public housing occupancy. The presence of these unobservables is likely to result in a correlation between the error terms of the public housing equation and the unemployment equation. The simultaneous probit model ensures that this correlation is explicitly dealt with, as the correlation matrix of error terms is estimated. The relevance of this recursive specification is discussed in details in Section 4.3.

In summary, the observed variables $y_{1}$ and $y_{2}$ referring respectively to unemployment and public housing accommodation are defined by:

$$
\begin{aligned}
& y_{1}= \begin{cases}1 & \text { if } y_{1}^{*}>0 \\
0 & \text { otherwise }\end{cases} \\
& y_{2}= \begin{cases}1 & \text { if } y_{2}^{*}>0 \\
0 & \text { otherwise }\end{cases}
\end{aligned}
$$

where $y_{1}^{*}$ and $y_{2}^{*}$ are latent variables influencing the probability of unemployment and the probability to be renter in the public sector respectively.

The system of latent variables is as follows:

$$
\left\{\begin{array}{l}
y_{1}^{*}=\alpha y_{2}+\beta_{1} X+u_{1} \\
y_{2}^{*}=\beta_{2} X+\gamma Z+u_{2}
\end{array}\right.
$$

where $X$ is a vector of exogenous variables including a constant, individual's age and its square (expressed as units of ten years), nationality, diploma and previous occupation as well as the spouse's nationality and diploma (each of them being a set of dummy variables). For models estimated on the Housing Survey data, $X$ also include the unemployment rate of the urban unit. $Z$ is a vector of chosen instruments, which varies according to the studied sample (Housing Survey on the whole country, or Population Census for Lyon). $\alpha$ tests for the influence 
of public housing occupancy on unemployment probability.

As we assume that the sorting of households into public housing may be affected by unobserved characteristics influencing simultaneously unemployment and public housing accommodation, the correlation term between the residuals of the two probits $\left(u_{1}\right.$ and $\left.u_{2}\right)$ is supposed to be non-zero and equal to $\rho_{12}$. Individual contributions to the likelihood can be written as follows:

$$
P\left(y_{i 1}, y_{i 2}\right)=\Phi_{2}\left[q_{i 1}\left(\beta_{1} X_{i}+\alpha y_{i 2}\right), q_{i 2}\left(\beta_{2} X_{i}+\gamma Z_{i}\right), q_{i 1} q_{i 2} \rho_{12}\right]
$$

where $q_{i j}=2 y_{i j}-1$ is equal to 1 whenever $y_{i j}$ is 1 and to -1 whenever $y_{i j}$ is 0 , subscript $i$ denotes individual $i$ and $\Phi_{2}($.$) is the bivariate normal cumulative distribution function. The$ sample log-likelihood function is then:

$$
\ln L=\sum_{i}^{N} \ln P\left(y_{i 1}, y_{i 2}\right)
$$

Such a system can be estimated by a maximum likelihood method. Endogeneity tests amount to test the significance of the correlation coefficient of residuals (Greene, 1998). Note that for models estimated on the national sample, standard errors had to be corrected for within-city dependencies, using Huber ajusted standard errors (Wooldridge, 2003).

\subsection{Choice of instruments}

Existing instrumental variable estimations of the effect of tenure can be grouped according to the type of instrument they use: some use instruments measured at an aggregate level, others use instruments at the individual level. Among the first group, van Leuvensteijn and Koning (2004) estimate a simultaneous model of job duration and homeownership using the regional share of homeowners as instrument. Although their main identification strategy is based on multiple spells, Munch et al (2006 and 2008) also instrument homeownership by the percentage of homeowners at the aggregate level as a robustness check. The rationale for using 
such instruments is that, while regional homeownership rate naturally affects tenure status (through a supply effect), there is no a priori reason to believe that it has an impact on individual labor-market outcomes.

The second group of instruments uses variables measured at the individual level. Munch et al (2008) use the homeownership of parents in 1980 as an instrument in a simultaneous model of job duration, wages and homeownership. This relies on the assumption that after conditioning on education and labor-market outcomes, parents' homeownership status does not influence current labor-market outcome. In a different but related context, Currie and Yelowitz (2000) estimate the effect of public housing occupancy on housing quality and children grade repetition at school. They use the sex composition of children as an instrument, on the basis that sex composition influences the number of bedrooms needed (boys and girls being not required to share the same bedroom) and that families eligible for a larger apartment (i.e. with different sex children) are more likely to live in public housing projects.

We are going to use the same kind of logic for identifying the effect of public housing occupancy on the Lyon sample. As we already explained, the household composition and age of its members are taken into account by public housing agencies and are likely to explain public housing occupancy. Large families are given preferential attribution of public housing units and are less likely to leave public housing because they encounter difficulties in finding affordable housing, unless they have a high income. Furthermore, it has been observed that the number of children in a family depends on the gender composition of the first two children (Andersson et al., 2006). In our sample, households of which the first two children are of different genders seem more likely not to have a third child. Therefore, we may expect that the gender composition of the first two children is likely to influence the probability to be housed in the public sector. Goux and Maurin (2005) already used this kind of instrument on French data when focusing on the effect of housing overcrowding on educational attainment. They show in particular that the 
sex of the first two children influences the final number of children and the housing situation.

In a very close perspective, we instrument public housing occupancy by a dummy for the first child being a girl and the second a boy, this variable being supposed to decrease the probability among two-children families to have a third child and therefore the probability of public housing accommodation. In a second specification, we also combine this first exclusion with a dummy for having four children or more. In a third specification, we also take advantage of a third possibility: application to public housing is easier for people living already in the municipality where they want to find a public housing unit. As a consequence, we may expect households who lived formerly in the same municipality and moved, to be more likely to live in public housing. We therefore instrument public housing with a dummy variable indicating whether the last residential move of the household was within the same municipality. Because the last two specifications have two exclusions, we will be able to perform validity tests of the instruments.

This first identification strategy assumes that the estimation sample concerns a single, homogeneous housing market where procedures for getting public housing occupancy are similarly ruled. Moreover, this set of exclusions can only be used for families with two children and more. It is possible to use a different viewpoint and to rely on accross-cities comparisons for identifying the effect of public housing. Indeed, the share of public housing varies greatly between French cities. For instance, the lower rate of public housing among cities of more than 50,000 people is in Frejus (Provence-Alpes-Côte d'Azur region) with 7,0\% of public housing units in the housing stock and the higher rate is that of Reims (Champagne-Ardennes region) with $40,2 \%$ of public housing units. Of course, these differences affect the ceteris paribus probability of living in public housing. We exploit this variability for identifying the effect of public housing on unemployment.

Because different cities also have different labor-market situations, we control these dif- 
ferences by introducing the local unemployment rate in the unemployment equation for these specifications. Once these differences regarding the labor-market are controlled for, the validity of the chosen exclusion relies on the absence of sorting of individuals depending on their unobservable characteristics accross cities with different public housing shares. The low rate of mobility between regions in France allows to view this sorting as very unlikely. For this accrosscity sample, we will also use the gender composition of children as exclusion, although, because the sample mixes cities with different housing-market conditions, the effect of those variables on the residential situation is weaker.

The strength and the validity of these different instruments is discussed in further details in Section 4.2.

\subsection{Data}

As we already explained, our identification strategy of the effect of public housing relies on two different types of instruments, with two datasets that obey to different logics. The first dataset is a one-city sample concerning Lyon. The second dataset is a national sample taken from the French Housing Survey 2002.

Our first dataset is extracted from the 1999 French Population Census and concerns the urban unit of Lyon. Dealing with a single city allows us to analyze a rather homogeneous housing market, in which access conditions to the different segments of the housing market can be considered as common to all individuals. The share of public housing in the housing stock in Lyon is $20.1 \%$. Lyon is thus very representative of cities with a medium weight of public housing. Census data is interesting in such a context as it is the only data that gives a sample size sufficiently large as to provide accurate estimates of public housing effects for a given city. The sample we use consists in a 1:20th sample of individuals taken from the Census, for whom 
detailed personal, household, and housing characteristics are provided (age, gender, education, ${ }^{3}$ employment status, occupational status, household type, housing tenure, ...) along with the characteristics of the other members of the household. As we already explained, our study deals with heads of couple households (which here are all males), aged 19 to 64 and participating in the labor-market. Due to data availability on previous occupation, we deleted individuals who never worked, that is only 18 individuals. The final sample of individuals for the agglomeration of Lyon contains 10,473 individuals.

Lyon is the second largest city in France. Its agglomeration (defined here by its urban unit) extends over a $958 \mathrm{~km}^{2}$ area and hosts around 1.3 million inhabitants. ${ }^{4}$ Lyon, like many other French and European cities, presents a well-marked spatial structure, with some parts of the city characterized by a concentration of disadvantaged communities. Figure 1 maps the percentage of public housing at the neighborhood level in Lyon. The neighborhoods with the highest shares of public housing are found in the Eastern part of an intermediate ring. This pattern is very typical of French cities and plays a strong role in the spatial concentration of low-income households. In some of the neighborhoods displaying the highest unemployment rates, more than $50 \%$ of households (and even more than $70 \%$ for a few of them) are housed in the public renting sector. Those neighborhoods with high levels of unemployment and large shares of public housing have above average rates of low-educated, blue-collar workers and ethnic minorities.

\footnotetext{
${ }^{3}$ In the whole paper, the following education levels will be used: No diploma, At most lower secondary school, Vocational training, High school final diploma, University degree. They correspond to the following French categories: no reported diploma, CEP or Brevet, CAP or BEP, Baccalauréat, DEUG or above, respectively.

${ }^{4}$ The urban unit, unité urbaine in French, is a set of municipalities, the territory of which is covered by a built-up area of more than 2,000 inhabitants, and in which buildings are separated by no more than 200 meters. The urban unit of Lyon consists of 102 municipalities. For practical reasons, we added three municipalities which are enclosed within the urban unit of Lyon (Quincieux, Saint-Germain-au-Mont-D'Or and Poleymieux-au-MontD'Or).
} 
For each household that was already formed in the 1990 Census, we create a dummy variable indicating whether this household lived in the same municipality at that time. Because Lyon's urban unit has 105 municipalities, moves for residential reasons can frequently occur between municipalities of the urban unit. Our dummy variable amounts to opposing those who moved within the same municipality to households who did not moved or who moved between municipalities.

Our second dataset is taken from the French Housing Survey 2002. Housing Surveys are conducted about every four years in France on a sample of 40,000 households that are sampled for each survey so as to be representative of the French population and housing stock. Available data consists in the usual demographic and socio-economic characteristics such as household composition, members' diploma, status on the labor market. Detailed characteristics of the housing unit are surveyed, as well as a large range of financial data concerning housing prices, rents and household income.

We extract a sample from this dataset based on the same criteria that we used for the Lyon sample: couple households of which head has been employed at least once before, who is aged 19 to 64 and participates on the labor market. So as to deal with situations not too different from that of Lyon, we further restrict the sample to households in urban units of at least 50,000 people. ${ }^{5}$ We end up with a sample of 6,299 households. Using external data from the Population Census at an agregated level, we have calculated the unemployment rate and percentage of public housing units in the housing stock for each of these urban units.

Our sample covers 102 urban units of more than 50,000 inhabitants. Apart maybe from Paris, French urban units don't have a large spatial extension, which means that the housing market in each city can be viewed as homogeneous. The share of public housing varies greatly

\footnotetext{
${ }^{5}$ These urban units represent $52.2 \%$ of the French population.
} 
among these cities, from $7 \%$ to $40 \%$. Mean, first and last deciles are $22 \%, 12 \%$ and $31 \%$ respectively. This distribution exhibits thus a large variance and it is clear that households behavior on the housing market is not the same depending on this rate. The agregate unemployment rate in these cities varies from 7 to $25 \%$. As we noted before, it is not correlated to the share of public housing.

\section{First evidence and discussion of instruments}

In this section, we present in turn some descriptive statistics on our samples in both datasets and discuss the strength and validity of the instruments, as well as the relevance of the recursive model specification.

\subsection{Public housing, demography and unemployment: sample statistics}

Table 1 provides some sample statistics by employment status (employed versus unemployed) and tenure type (tenants in the public sector versus all other types of tenure) for the national sample and the Lyon sample. It is worth recalling that these are samples of couple households with head aged 19 to 64 , which explains characteristics that are slightly different from that of the whole population.

[Insert Table 1 about here]

Public tenants represent $21.7 \%$ of individuals in our national sample, and $19.2 \%$ in Lyon. Other individuals are either renters in the private sector or homeowners $(21.7 \%$ and $52.9 \%$ respectively for the national sample; $26.1 \%$ and $50.9 \%$ for Lyon). In both datasets, public renters are in general younger compared to other type of tenures. They are more often of foreign nationality, have lower educational levels and occupational statuses. As expected, unemployment 
rates vary markedly with respect to housing tenure: public housing tenants are more often in unemployment than other types of tenure (15.7\% and 5.8\% respectively for the national sample; $12.8 \%$ and $4.9 \%$ for Lyon). However, these differences can largely be explained by differences in other characteristics such as education.

Concerning family composition, public renters have larger families than other types of tenures. Indeed, $26.7 \%$ of public renters in Lyon have at least three children, against $14.9 \%$ in the other tenures. Families having four children or more are also more prevalent among public housing tenants (11.5\% compared to $3.6 \%)$. Percentages for the national sample are roughly similar. The sex composition of children also differs between public renters and other types of tenure. Indeed, among households having at least two children, $22.4 \%$ of public renters in Lyon have a girl then a boy as their two oldest children, compared to $25.3 \%$ for other tenure types. This is in line with our hypothesis that families having a girl then a boy as their two oldest children are less likely to have a third child and therefore to be housed in the public housing sector. Corresponding figures for the national sample are $21.5 \%$ and $23.3 \%$ respectively. Note also that the gender composition of children does not differ much according to the employment status (the percentage of two-children households having a girl then a boy being $24.6 \%$ for the employed and $25.5 \%$ for the unemployed in the Lyon sample).

In Lyon, public renters are also more likely to have moved within the same municipality during the inter-Census period (that is between 1990 and 1999), which suggests that it is easier to apply for a public housing unit when one already lives within the same municipality. Differences in within-municipality mobility rates between public tenants and other tenures are also much more important than corresponding differences between employed and unemployed persons (a $10 \%$ gap between tenure types, against a $4 \%$ gap between employment statuses). 


\subsection{Instruments relevance and validity}

The choice of instrumental variables is always based on two criteria: the relevance of the instrument (i.e. whether it is correlated with the endogenous variable conditionally on all the other covariates in the equation) and its validity (i.e. whether it is orthogonal to the error term of the equation of interest). The first condition amounts to having $\operatorname{Cov}\left(y_{2}^{*}, Z \mid.\right) \neq 0$ with $y_{2}^{*}$ the endogenous variable in the interest equation and $Z$ the vector of instruments. The second condition can formally be written as $\operatorname{Cov}\left(Z, u_{1}\right)=0$ with $u_{1}$ the error term in the interest equation. In the following, we give arguments showing why these two conditions hold for the set of exclusions that we use in our two samples.

Statistical tests for these conditions are common in linear models, and we rely on linear probability specifications of our model to perform these tests. Linear probability models have heteroskedastic errors that will produce inconsistent standard error of instrumental variable usual estimates. ${ }^{6}$ Furthermore, the usual tests for instruments relevance and valididity are inappropriate in the case of heteroskedastic errors. The standard method in this case is a GMM estimation, for which Baum et al. (2003) discuss the strength and validity tests of instruments.

In our one-city sample, we use three different instruments in different combinations: a dummy for the first child being a girl and the second a boy (this variable is restricted to families with two or more children), the fact that the household has four children or more and whether it moved within the same municipality. We begin by discussing the relevance of these instruments, i.e. whether they impact public housing occupancy strongly enough. The use of our first two instruments rest on the following ideas: (1) large families need more floor space and are therefore, all other things being equal, more likely to apply for accommodation in public housing; they are moreover considered has prioritary by public housing agencies; (2) parents have a preference

\footnotetext{
${ }^{6}$ Tests of heteroskedasticity of linear probability models for our different specifications have been performed. All of them reject the hypothesis of homoskedastic errors.
} 
for having children of different gender, and those who have a boy and a girl as their first two children are less likely to have a third child.

To give some support to this second hypothesis, we look at the effect of the first two children genders on the probability of having a third child, among families with at least two children (Table 2). We observe that, conditionally on socio-demographic characteristics such as age and diploma, having a girl followed by a boy decreases the probability of having a third child, compared to same-sex siblings, by 3.6 and 4.7 probability points in the Lyon sample and in the national sample respectively. Having a girl and then a boy have an effect of the same magnitude though less significant. As a consequence, we keep the dummy variable for the first child of the household being a girl and the second a boy as a shifter of public housing occupancy. Our hypothesis is that, compared to all other types of households, the "girl-boy" households are more likely to have only two children and thus less likely ceteris paribus to be tenants in the public sector. Simple probit estimates of public housing occupancy confirm this relationship: in three different specifications, the "girl-boy" variable has a significant and negative effect on the probability of public housing occupancy, after controlling for the exogenous variables introduced in our model (see columns 1-3 in Table 3). In column (2), the effect of this variable is estimated jointly with a dummy for having four children and more. This second variable significantly affects the probability of public housing without changing the impact of the children-gender variable.

[Insert Table 2 about here]

[Insert Table 3 about here]

In column (3), we consider a third exclusion indicating whether the household moved within the municipality during the inter-Census period. Lyon's urban unit being divided between 105 municipalities, residential moves can often occur between these municipalities even for short- 
distance moves. However, application to public housing has to be done in local agencies and access seems to be easier for households which better know the local conditions and maybe have access to local social networks that are able to ease the procedure. Therefore, residential moves of public housing renters seem more constrained and are more likely to occur within a municipality. Actually, this variable affects significantly the probability of public housing occupancy.

Finally, to conclude on our instruments' relevance, we perform F-tests of the joint significance of the instruments in a linear probability model of public housing occupancy. Instruments are considered strong enough, following Staiger and Stock (1997), if the F-test for joint significancy is higher than 10. Our results show that the children-gender variable alone is not strong enough for an IV estimate of the effet of public housing to be unbiased ( $\mathrm{F}=5.13)$. However, this exclusion is strong enough as soon as it is combined with one of the other two exclusions: the $\mathrm{F}$ statistic is 14.41 when gender composition is used in combinaison with having four children or more and 13.89 when used with our mobility indicator.

We now turn to the assessment of instrument validity (that is whether our instruments are orthogonal to the error term in the unemployment equation). Our first instrument should not be considered as correlated to the error term. Indeed, it seems obvious that the children gender is random. It has not been chosen by the household and there is no reason for it to affect the father's unemployment probability. Previous papers using this instrument clearly showed that it can be considered as random and exogenous to the labor-market situation of the parents (see Angrist and Evans, 1998; Goux and Maurin, 2005).

Turning to our second instrument, we assume that having four children is exogenous with respect to the father's situation on the labor-market, after controlling for the effect of the other covariates. Because this hypothesis is questionable, we perform a standard overidentification test based on the estimation of a linear probability model with the gender composition of children and the number of children as instruments. One knows that overidentification tests can fail to reject 
the null hypothesis if the two instruments are endogenous but induce biases of similar sign and magnitude. We argue that the presence in the test of the gender-composition variable, of which orthogonality is clear, allows to consider the overidentification tests as reliable. The Hansen's J statistic (reported at the bottom of Table 3) shows that the null hypothesis of orthogonality of these two instruments can not be rejected at any usual confidence level. As will be clear in the following, our central result does not depend on the quality of this exclusion.

Finally, we perform a similar overidentification test for our third specification, i.e. for a model using the within-municipality mobility and children gender composition as instruments. For this specification, the p-value of the Hansen J statistics is 0.266 , which indicates that the null hypothesis of orthogonality of these two instruments cannot be rejected. Again, the reliability of this overidentification test is ensured, first by the fact that the gender composition of children can safely be considered as orthogonal, second by the fact that these two exclusions rely on very different logics. It seems therefore very unlikely that these two instruments would lead to similar biases that would make the overidentification test falsely reject the null hypothesis of orthogonality.

In the national sample, our main exclusion is at the aggregate level: it is the percentage of public housing in the housing stock in the city. The relevance of this instrument is obvious: households in cities with a high level of public housing are more likely to be tenants in the public sector. Accordingly, the strength of this instrument is large. The F test of significativity of the instrument in the first stage estimation is 93.8 (see column (4) of Table 3).

The validity of this instrumental variable is ensured as long as the unobservables that affect the percentage of public housing does not affect unemployment probability and that households do not sort themselves between urban units based on unobservable characteristics. As to the first relation, it is useful to explain the variation in the weight of public housing between cities. In France, public housing projects were largely built during the 60's and 70's and the percentage 
of public housing in the housing stock today is particularly high in the north-east part of the country which had suffered from destructions during World War II. The reason for having built public housing projects relates to past local considerations that are not particularly linked to the current economic situation. In particular, it is worth noting that there is no correlation between the weight of public housing in the city and the percentage of unemployment at the agregate level (correlation is 0.06 and is statistically insignificant). Moreover, we introduce the city unemployment rate in the unemployment equation. This means that the agregate variation of unemployment is already taken into account by this exogenous variable and there is no reason for the percentage of public housing to be correlated to the error term conditionally on this control. Moreover, the standard errors in the corresponding estimations are robust standard errors which are corrected for correlation within cities. As to the sorting of households, it is worth noting that residential moves between urban units are inter-regional migrations which are not very frequent in France (Détang-Dessendre et al., 2008).

Finally, we also performed an overidentification test in the specification that use the children gender composition and the percentage of public housing in the city as exclusions. Again, we fail to reject the null hypothesis of orthogonality of this set of instruments with a p-value of the Hansen J statistics of 0.636 .

\subsection{Discussion of the recursivity hypothesis}

A potential problem affecting our identification strategy is the coherency condition that prevents the inclusion of the unemployment variable in the public housing equation. The question is to know whether not including unemployment in the residential equation hinders the proper identification of the public housing effect.

Of course, the economic situation of the household's members is taken into account by public housing agencies at the time of application. However, the length of housing occupancy 
is important with respect to unemployment durations: more than a third of public housing tenants have been occupying their dwelling for more than 8 years. Therefore, it is maybe not unemployment that affects public housing occupancy, but rather the other characteristics of the household that determine unemployment risk. To test the hypothesis that unemployment does not influence public housing occupancy conditionally on the other covariates, we estimated the reverse system: a simultaneous probit model of unemployment and public housing, in which unemployment is considered as a determinant of public housing accommodation and no effect of public housing on unemployment is assumed, so that the coherency condition is satisfied. In the Housing Survey sample, we use the city unemployment rate as an exclusion to identify the effect of unemployment. In the Census sample, we are not able to control for the endogeneity of unemployment. In both cases, and surprisingly enough, we do not observe any effect of unemployment on the probability to be tenant in the public sector (the $\mathrm{z}$ statistic for the unemployment coefficient is 0.52 in the first case and 0.27 in the second case, showing the absence of any significant effet of unemployment on the probability of public housing occupancy). ${ }^{7}$

This result probably ensues from the inertia of public housing occupants: once in public housing, households have very low incentives to leave it. In other words, those findings could be explained by the fact that, although unemployed individuals may be more likely to obtain a public housing unit, we consider here the cross section of all public housing renters, who are likely to have left unemployment but remained in the public housing sector in order to benefit from reduced housing rents.

\section{Results}

In this section, we present in turn results of simple probit models of unemployment (Section 5.1) and results of the simultaneous probit model (Section 5.2). We also provide a last robustness

\footnotetext{
${ }^{7}$ Detailed results available from the authors on request.
} 
check using a counterfactual exercise in which we impose some correlation between unobservables affecting unemployment and public housing occupancy (Section 5.3).

\subsection{Probit estimates of the unemployment equation}

Table 4 gives marginal effects for the probit of unemployment for the two samples, for all households (columns 1 and 3) and for those with at least two children (columns 2 and 4). We find very conventional results regarding individual determinants of employment status. Young individuals are more often unemployed, and the probability to be unemployed declines until the age of 43 , after which it increases again, which is in line with observed unemployment rates by age. Individuals without any diploma or with only a short vocational training are more likely not to have a job, whereas people who were previously independent workers or executives are less unemployed than others. The two variables related to nationality have significant effects: the probability of unemployment of people of foreign nationality is increased by 5.3 points in Lyon sample and 4.2 points in the national sample, compared with French individuals born in France. A weaker effect is found for individuals of French nationality born abroad.

[Insert Table 4 about here]

As to the effect of public housing, these probit estimates show that the unemployment probability increases with public housing occupancy. In Lyon sample, public housing tenants have an unemployment probability higher by 3.5 points than households in other tenures (3.4 for households with two children and more). In the national sample, this estimated marginal effect of public housing occupancy is 5.6 points ( 7.0 for households with two children and more). If we compare this effect to that of nationality, we observe that the impact of public housing is a little smaller in Lyon sample and a little higher in the national sample, but of the same magnitude. However, these estimation results very likely suffer from an endogeneity bias. 


\subsection{Simultaneous probit model estimates}

Table 5 presents the marginal effects estimated from the simultaneous probit model for Lyon's sample for three different specifications concerning households with two children or more. Table 6 presents the results of the simultaneous probit model for the Housing Survey sample. In this table, model 1 concerns the whole sample and model 2 is restricted to households with two children or more. Marginal effects of exogenous variables in the unemployment equation being very similar to the simple probit results, we do not comment on them here.

[Insert Table 5 about here]

[Insert Table 6 about here]

We look first at the determinants of public housing occupancy for Census data (Table 5). Recall that we are focusing on households with at least two children, in order to be able to use the gender composition of children as instrument. Public housing occupancy decreases steadily with age. The other demographic variables, that are used as exclusions, have the expected effects. Households with four children and more are more likely to rent a public housing unit compared to households with two or three children (Model 2). Households with the oldest child being a girl and the second a boy are less likely to be in public housing. The effect is stable accross the three specifications where the variable is used. Household heads of foreign nationality are by about 13 probability points more likely to be in public housing. The origin of the spouse have a similar effect, though of weaker magnitude. These observations might reflect the fact that foreign individuals are pushed toward the public housing sector due to discrimination on the housing market.

As far as socioeconomic variables are concerned, occupational status along with education explains the propensity to live in a public housing unit. Blue-collar workers and office workers 
are by 16 points and 13 points more likely to rent a public housing unit than intermediate professions (the reference category). The effect of educational level of the household head is less clear. Contrarily, the spouse's educational level strongly affects public housing occupancy: the possibility to have or not a second wage in the household (low educated women having a weak incentive to take part in the labor-force) is naturally important in determining residential choices and is considered by public housing offices during the application process.

Results based on the Housing Survey data are very close to those on Census data (Table 6). One difference is that the effect of age on this dataset is weaker (Model 2 in Table 6) but the minimum is very close. This difference is not surprising as the conditions on the housing market might differ in Lyon compared to the set of all urban units that are in the Housing Survey sample.

Turning to the unemployment equation, our results show that public housing occupancy does not have any impact on unemployment. Indeed, whatever the set of instruments used, the dataset (Population census or Housing Survey) and, for Housing Survey data, the studied sample (all households or households with at least two children), the marginal effect of public housing occupancy on unemployment is not significantly different from zero at a $10 \%$ level. This is in contradiction with positive effects obtained in "naive" probit estimates and shows that accounting for endogeneity rules out any effect of public housing on unemployment.

The robustness of these results is conditional on the quality of the different instruments. All the sets of instruments that we use pass the standard relevance and overidentification tests. However, these tests may be considered as possibly missleading under certain circumstances. We argue that even with this pessimistic viewpoint, the specification in which the only exclusion is the gender composition of children prooves the absence of any effect of public housing on unemployment. 
Indeed, as argued in section 4.2 there are good reasons to view the gender composition of children as exogenous to the father's behavior on the labor-market. The only drawback of this instrument is that it is weak. However, it is easy to test the null hypothesis that the endogenous variable has no effect on unemployment using a Stock-Wright statistic, which is robut in the presence of weak instruments (Stock and Wright, 2000). The p-value associated with this test in the specification with the children gender composition as the sole instrument is $0.47 .^{8}$ This test is another argument showing that we can safely consider that public housing occupancy has no effect on the employment status of public housing tenants.

Estimated correlation coefficients of error terms are positive in all cases. This suggests that unobserved determinants of public housing occupancy are positively correlated to unobserved characteristics affecting unemployment. These correlation coefficients are however unsignificant. We will come back to this point in the next section.

\subsection{Robustness check}

Our results suggest that public housing does not have any detrimental impact on unemployment on the basis of our instruments. However, because the validity of instrumental variables is often controversial, it is worth providing a final robustness check that is independent on the quality of our instruments. Our analysis here is similar to the one used by Altonji et al (2005) and is aimed at determining the amount of selection on unobservables that could explain the whole effect of public housing on unemployment. The principle of this analysis rests on the idea that in the absence of any valid instrument (i.e. in the case where the exogenous variables influencing unemployment and public housing are exactly the same), the system of equations given by 3.3 can be estimated while fixing the value of the correlation coefficient $\rho_{12}$. In doing so, we impose a certain amount of correlation between unobservables affecting the two outcomes.

\footnotetext{
${ }^{8}$ More specifically, the statistic is 0.52 and is distributed Chi-square with one degree of freedom.
} 
Then, by repeating this operation for increasing values of $\rho_{12}$ and examining coefficient estimates on the public housing variable in the unemployment equation, one can determine the degree of correlation between unobservables that is needed to make the effect of public housing unsignificant.

Table 7 reports estimates of public housing effects obtained from simultaneous probit models that include the same set of exogenous variables in both equations (that is age and its square, nationality, education, previous occupation, spouse's nationality and education) but no instrument. We vary $\rho_{12}$ from 0 (which corresponds to the single probit model of unemployment of Table 4) to 0.25 and repeat the analyses for our two datasets, on the whole sample as well as on the sample of households having at least two children. For the full sample on Lyon (panel A of Table 7 ), the marginal effect of public housing is 0.035 and is significantly different from zero when $\rho=0$. This effect declines gradually as $\rho$ increases and becomes non significantly different from zero when $\rho$ jumps from 0.10 to 0.15 . Similar results are found for the sample of Lyon's households with at least two children (panel B). For the national sample, marginal effects of public housing when $\rho=0$ are 0.056 for all households, and 0.070 for households with at least two children. In these cases, the public housing effect becomes non significant when $\rho$ jumps from 0.15 to 0.20 for all households (panel C) and from 0.20 to 0.25 for those with at least two children (panel D).

[Insert Table 7 about here]

Clearly, these are only small correlation coefficients which are likely to arise in the context we are studying. Indeed, a selection in the public housing sector of households based on their unobserved characteristics can occur over time. For instance, for a given educational level, some individuals will be successful in their job and will improve their positions in their firm over time. They are likely to have increased wages that will allow them to leave the public housing sector and they are also likely to have a lower risk of unemployment. If such a selection occurs, households 
who stay in public housing have on the contrary detrimental unobserved characteristics in terms of labor-market outcomes, which would explain the effect of public housing in probit models of unemployment. The conclusion we draw is thus a strong one: public housing occupancy is not likely to have any detrimental impact on unemployment, as only a small amount of selection on unobservables is enough to completely wipe out the positive effect found in 'naive' single probit estimates.

\section{Conclusion}

Estimating properly the effect of public housing on unemployment is crucial because it has important policy implications. It is however a difficult task, because the two behaviors are intrinsically related. Actually, there is no ideal method for dealing with the endogeneity issue in this context. We showed why a multiple-spells method is not really possible in our case, which explains that we chose to resort to an instrumental method.

Our contribution in this area consists in using several convergent methods. First, we estimate the same model on two samples having very different logics. On one sample, we instrument public housing with the gender composition of children, the exogeneity of which has been thoroughly documented in previous studies. Although this instrument is weak in our case, we show that it still enables us to test for the nullity of the effect of public housing on unemployment. On the other sample, we take advantage of the variation in the share of public housing at the city level to identify the effect of public housing occupancy. This allows us to estimate our model for all couple households, whatever the number of children. Finally, we also perform a robustness check that consists in measuring the amount of correlation between unobservables that would be sufficient to explain the whole effect of public housing on unemployment. As the corresponding level of correlation is rather low, we conclude that this check reinforce our central result of no effect of public housing occupancy on unemployment. 
This result is important from a public policy viewpoint. Actually, even if the mobility of public tenants is markedly lower than the mobility of other tenants, we show that this does not impact unemployment probability. This sheds some light on the debate between housing subsidies and public housing. On one side, housing subsidies are known to contribute to rent increases. On the other side, public housing might generate detrimental externalities. Currie and Yelowitz (2000) showed that children are positively affected by living in a public housing project. We show that this is not ruled out by a negative effect on the parents' outcomes on the labor market. However, public housing in France is known to be a powerful source of urban segregation. It is then on the research agenda to show that the spatial concentration of low-income households generated by public housing projects does not harm these households either. 


\section{References}

Altonji, J.G., Elder, T.E., Taber C.R. (2005) Selection on Observed and Unobserved Variables: Assessing the Effectiveness of Catholic Schools. Journal of Political Economy, 113: 151-184.

Andersson, G., Hank, K., Ronsen, M., Vikat, A. (2006) Gendering family composition : sex preferences for children and childbearing behaviour in the nordic countries. Demography, 43: $255-267$.

Angrist, J. and Evans, W. (1998) Children and their parent's labor supply: evidence from exogenous variation in family size. American Economic Review, 88: 450-477.

Baum C.F., Schaffer M.E.,Stillman S. (2003) Instrumental variables and GMM: Estimation and testing. Stata Journal, 3: 1-31.

Battu, H., Ma, A., Phimister, E. (2008) Housing tenure, job mobility and unemployment in the UK. The Economic Journal, 118: 311-328.

Blundell, R. and Smith, R.J. (1994) Coherency and estimation in simultaneous models with censored or qualitative dependent variables. Journal of Econometrics, 64: 355-373.

Currie, J. and Yelowitz, A. (2000) Are public housing projects good for kids? Journal of Public Economics, 75: 99-124.

Cutler, D.M. and Glaeser, E.L. (1997) Are ghettos good or bad? Quarterly Journal of Economics, 112: 827-872.

Debrand, T. and Taffin, C. (2005) La mobilité résidentielle depuis 20 ans: des facteurs structurels aux effets de la conjoncture. Economie et Statistique, 381-382: 125-145.

de Graaff, T., van Leuvensteijn, M. van Ewijk, C. (2009) Homeownership, social renting and labour mobility across Europe. In M. van Leuvensteijn and C. van Ewijk (eds) Homeownership 
and the Labour Market in Europe. Oxford: Oxford University Press (forthcoming).

Détang-Dessendre, C., Goffette-Nagot, F., Piguet, V. (2008) Life cycle and migration to urban and rural areas: estimation of a mixed logit model on French data. Journal of Regional Science, 48: $789-824$.

Fack, G. (2006) Are housing benefit an effective way to redistribute income? Evidence from a natural experiment in France. Labour Economics, 13: 747-777.

Flatau, P., Forbes, M., Hendershott, P.H., Wood, G. (2003) Homeownership and unemployment: the roles of leverage and public housing. NBER Working Paper, 10021.

Goux, D. and Maurin, E. (2005) The effect of overcrowded housing on children's performance at school. Journal of Public Economics, 89: 797-819.

Granovetter, M. (1995) Getting a Job: a study of contacts and careers. 2nd Edition. Chicago: University of Chicago Press.

Greene, W.H. (1998) Gender Economics Courses in Liberal Arts Colleges: Further Results. Journal of Economic Education, 29: 291-300.

Hughes, G., McCormick, B. (1987) Housing markets, unemployment and labour mobility in the UK. European Economic Review, 91: 919-937.

Ihlanfeldt, K.R. (1997) Information on the spatial distribution of job opportunities within metropolitan areas. Journal of Urban Economics, 41: 218-242.

Jacob, B.A. (2004) Public housing, housing vouchers, and student achievement: Evidence from public housing demolitions in Chicago. American Economic Review, 94: 233-258.

Jacquot, A. (2007) L'occupation du parc HLM: un éclairage à partir des Enquêtes Logement. Mimeo, INSEE. 
Maddala, G.S. (1983) Limited-dependent and Qualitative Variables in Econometrics. Cambridge: Cambridge University Press.

Munch, J.R., Rosholm, M., Svarer, M. (2008) Home ownership, job duration, and wages. Journal of Urban Economics, 63: 130-145.

Munch, J.R., Rosholm, M., Svarer, M. (2006) Are homeowners really more unemployed? The Economic Journal, 116: 991-1013.

Newman, S.J. and Harkness, J.M. (2002) The long-term effects of public housing on selfsufficiency. Journal of Policy Analysis and Management, 21: 21-43.

Oswald, A. (1996) A conjecture of the explanation for high unemployment in the industrialized nations: PartI. University of Warwick Economic Research Papers, 475.

Reingold, D. (1999) Social networks and the employment of the urban poor, Urban Studies, 35: 1907-1932.

Smith, T.E. and ZENOU, Y. (2003) Spatial mismatch, search effort, and urban spatial structure. Journal of Urban Economics, 54: 129-156.

Staiger, D. and Stock, J.H. (1997) Instrumental Variables Regression with Weak Instruments. Econometrica, 65: 557-586.

Stock, J.H. and Wright, J.H. (2000) GMM with Weak Identification. Econometrica, 68: 10551096.

Svarer, M., Rosholm, M., Munch, J.R. (2005) Rent control and unemployment duration. Journal of Public Economics, 89: 2165-2181.

van Leuvensteijn, M. and Koning, P. (2004) The effect of home-ownership on labor mobility in the Netherlands. Journal of Urban Economics, 55: 580-596. 
Wasmer, E. and Zenou, Y. (2006) Equilibrium search unemployment with explicit spatial frictions. Labour Economics, 13: 143-165.

Wooldridge, J. (2003) Cluster-sample methods in applied econometrics. American Economic Review, 93: 133-138. 


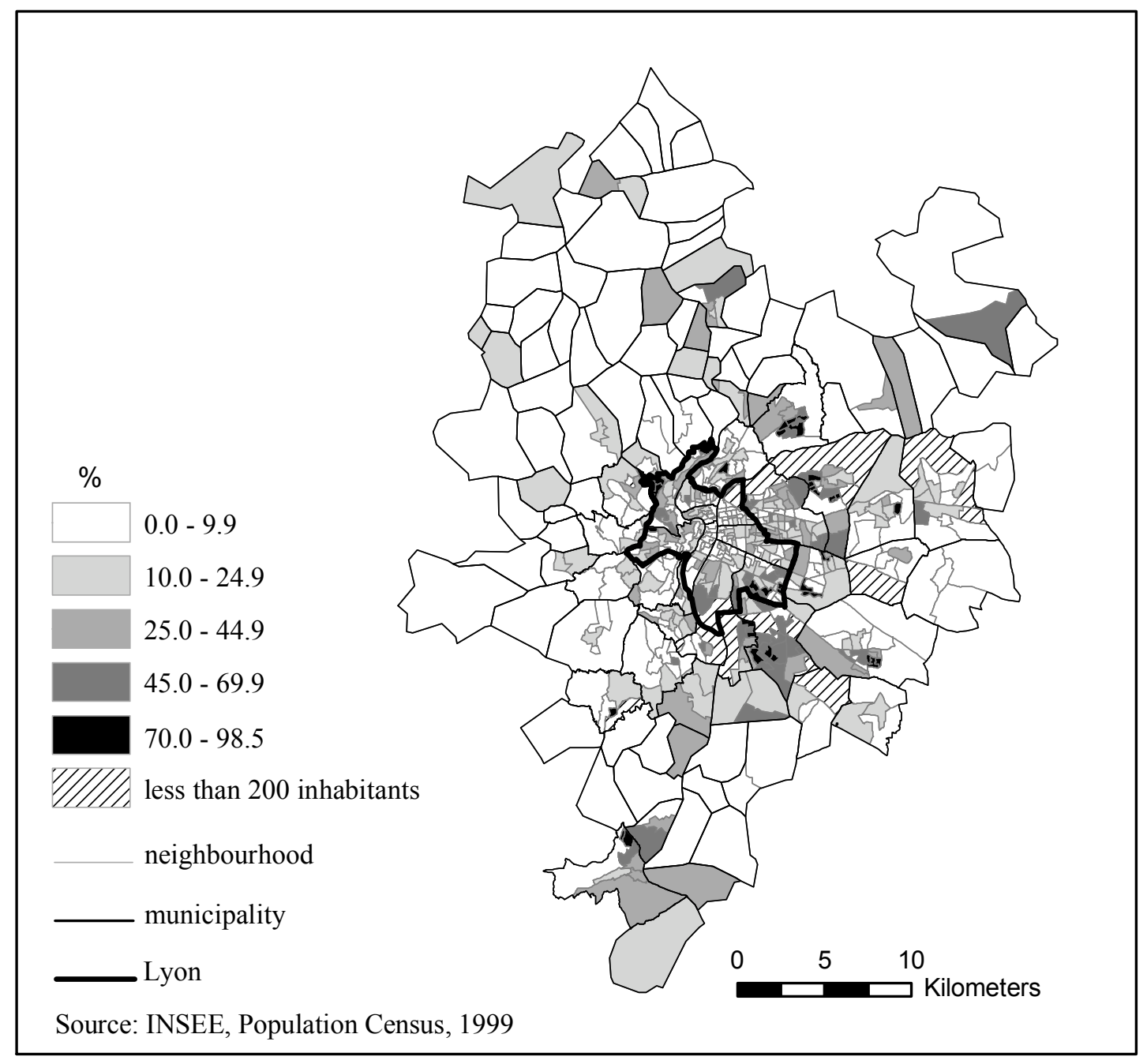

Figure 1: Percentage of housing units belonging to the public sector in Lyon 


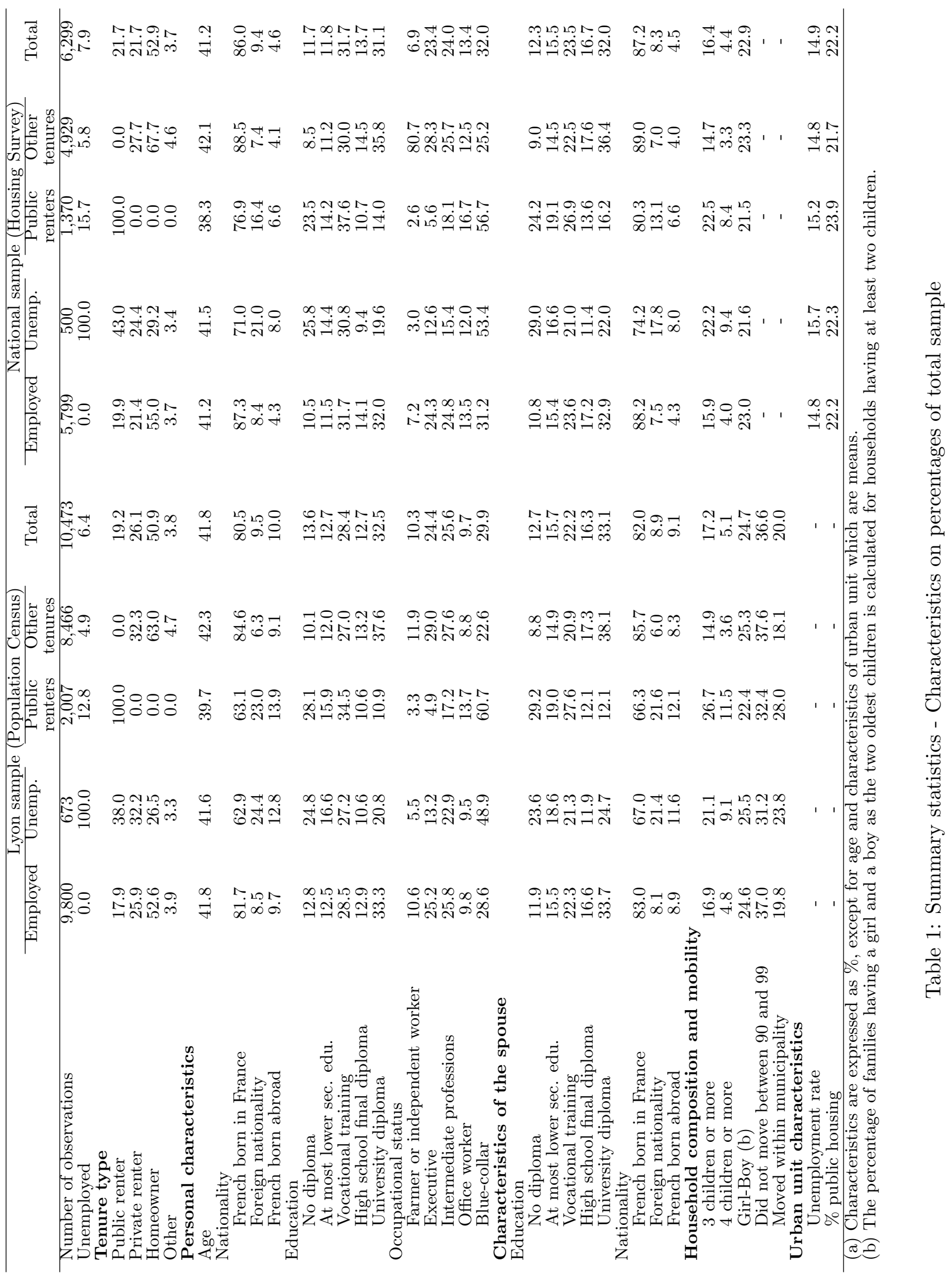




\begin{tabular}{lcc}
\hline & $\begin{array}{c}\text { Lyon sample } \\
\text { (Population Census) }\end{array}$ & $\begin{array}{c}\text { National sample } \\
\text { (Housing Survey) }\end{array}$ \\
\hline Girl - Boy & $-0.036^{* *}$ & $-0.047^{* *}$ \\
& $(0.017)$ & $(0.022)$ \\
Boy - Girl & $-0.031^{*}$ & $-0.038^{*}$ \\
& $(0.017)$ & $(0.022)$ \\
Control variables & $\mathrm{Y}$ & $\mathrm{Y}$ \\
\hline Pseudo-R $^{2}$ & 0.0726 & 0.0632 \\
Number of observations & 4,849 & 2,897 \\
\hline Notes: ${ }^{* * *},{ }^{* *}$ and ${ }^{*}$ denote significance at the 1\%, 5\% and 10\% level respectively. \\
Figures in brackets give standard errors. All models also include: a constant, age, \\
squared-age, nationality, diploma, occupational status, spouse's diploma and nation- \\
ality.
\end{tabular}

Table 2: Marginal effects of first two children gender on the probability of having a third child 


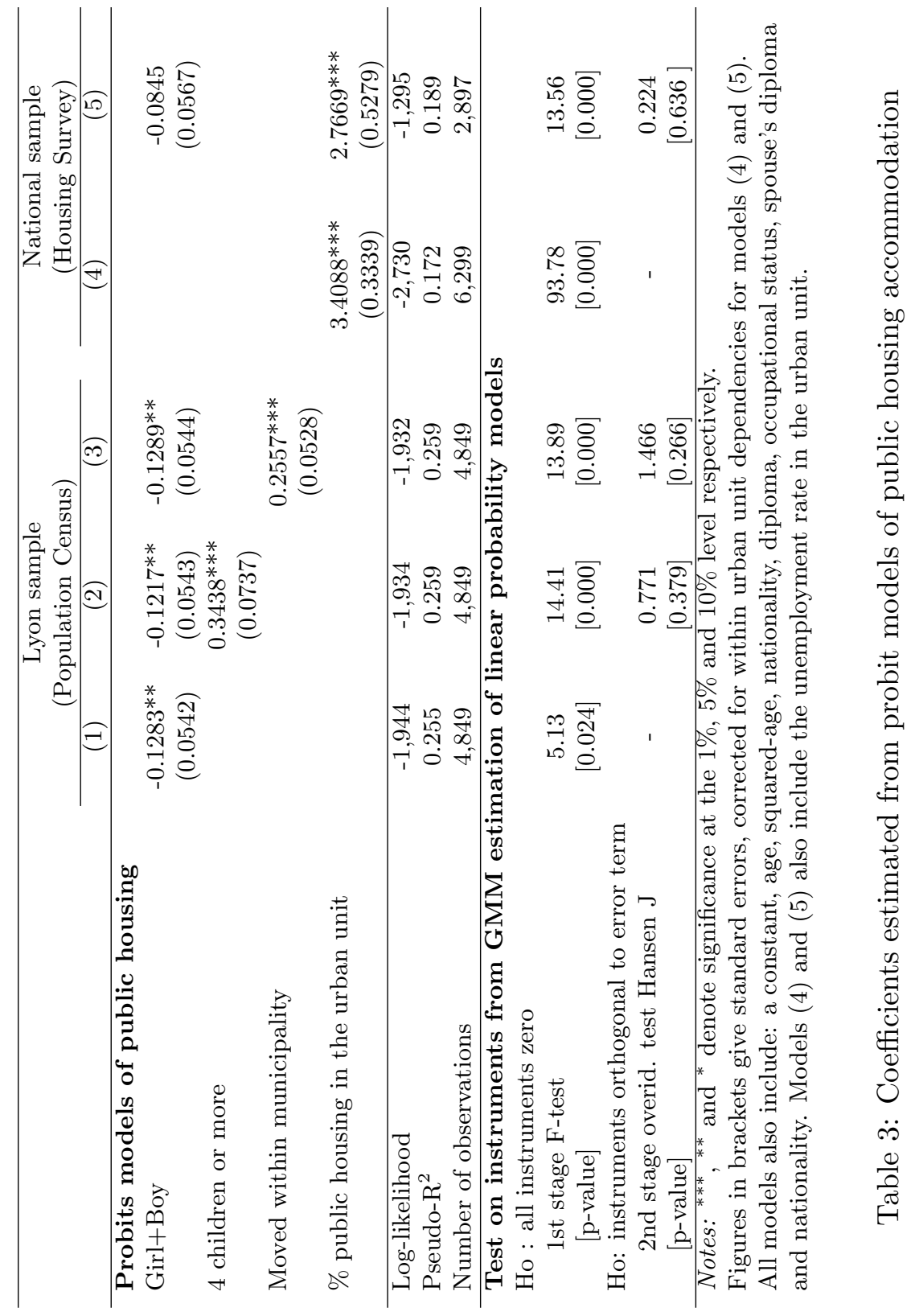




\begin{tabular}{|c|c|c|c|c|}
\hline & \multicolumn{2}{|c|}{$\begin{array}{c}\text { Lyon sample } \\
\text { (Population Census) }\end{array}$} & \multicolumn{2}{|c|}{$\begin{array}{l}\text { National sample } \\
\text { (Housing Survey) }\end{array}$} \\
\hline & $\begin{array}{l}\text { All } \\
(1)\end{array}$ & $\geq \underset{(2)}{2 \text { children }}$ & $\begin{array}{l}\text { All } \\
(3)\end{array}$ & $\begin{array}{l}\geq 2 \text { children } \\
(4)\end{array}$ \\
\hline Public housing & $\begin{array}{c}0.0351^{* * *} \\
(0.0069)\end{array}$ & $\begin{array}{c}0.0338^{* * *} \\
(0.0091)\end{array}$ & $\begin{array}{c}0.0557^{* * *} \\
(0.0084)\end{array}$ & $\begin{array}{c}0.0696^{* * *} \\
(0.0126)\end{array}$ \\
\hline Personal characteristics & & & & \\
\hline Age (x 10 yrs) & $\begin{array}{c}-0.0805^{* * *} \\
(0.0189)\end{array}$ & $\begin{array}{c}-0.0782^{* *} \\
(0.0344)\end{array}$ & $\begin{array}{c}-0.1594^{* * *} \\
(0.0198)\end{array}$ & $\begin{array}{c}-0.1619^{* * *} \\
(0.0312)\end{array}$ \\
\hline Squared-age (x 10 yrs) & $\begin{array}{c}0.0093^{* * *} \\
(0.0022)\end{array}$ & $\begin{array}{c}0.0086^{* *} \\
(0.0040)\end{array}$ & $\begin{array}{c}0.0196 * * * \\
(0.0022)\end{array}$ & $\begin{array}{c}0.0193^{* * *} \\
(0.0035)\end{array}$ \\
\hline Nationality & & & & \\
\hline French born in France & Ref. & Ref. & Ref. & Ref. \\
\hline Foreign nationality & $\begin{array}{c}0.0530 * * * \\
(0.0129)\end{array}$ & $\begin{array}{c}0.0687^{* * *} * \\
(0.0185)\end{array}$ & $\begin{array}{c}0.0425^{* * *} \\
(0.0167)\end{array}$ & $\begin{array}{c}0.0389^{* *} \\
(0.0193)\end{array}$ \\
\hline French born abroad & $\begin{array}{l}0.0191^{* *} \\
(0.0089)\end{array}$ & $\begin{array}{c}0.0383^{* * *} \\
(0.0130)\end{array}$ & $\begin{array}{c}0.0360 * * * \\
(0.0163)\end{array}$ & $\begin{array}{c}0.0277 \\
(0.0203)\end{array}$ \\
\hline Education & & & & \\
\hline No diploma & $\begin{array}{l}0.0183^{*} \\
(0.0108)\end{array}$ & $\begin{array}{c}0.0174 \\
(0.0149)\end{array}$ & $\begin{array}{r}0.0288^{* *} \\
(0.0133)\end{array}$ & $\begin{array}{c}0.0124 \\
(0.0157)\end{array}$ \\
\hline At most lower sec. edu. & $\begin{array}{l}0.0191^{*} \\
(0.0108)\end{array}$ & $\begin{array}{c}0.0143 \\
(0.0152)\end{array}$ & $\begin{array}{l}0.0258^{*} \\
(0.0155)\end{array}$ & $\begin{array}{c}0.0190 \\
(0.0178)\end{array}$ \\
\hline Vocational training & $\begin{array}{c}0.0027 \\
(0.0082)\end{array}$ & $\begin{array}{c}0.0016 \\
(0.0118)\end{array}$ & $\begin{array}{c}0.0072 \\
(0.0112)\end{array}$ & $\begin{array}{c}0.0046 \\
(0.0133)\end{array}$ \\
\hline High school final diploma & Ref. & Ref. & Ref. & Ref. \\
\hline University diploma & $\begin{array}{l}-0.0014 \\
(0.0084)\end{array}$ & $\begin{array}{c}0.0157 \\
(0.0134)\end{array}$ & $\begin{array}{c}0.0039 \\
(0.0096)\end{array}$ & $\begin{array}{c}-0.0063 \\
(0.0168)\end{array}$ \\
\hline Occupational status & & & Ref. & Ref. \\
\hline Farmer or independent worker & $\begin{array}{c}-0.0274^{* * *} \\
(0.0064)\end{array}$ & $\begin{array}{c}-0.0180^{*} \\
(0.0093)\end{array}$ & $\begin{array}{c}-0.0368 * * * \\
(0.0077)\end{array}$ & $\begin{array}{l}-0.0076 \\
(0.0154)\end{array}$ \\
\hline Executive & $\begin{array}{c}-0.0181^{* * *} \\
(0.0064)\end{array}$ & $\begin{array}{c}-0.0153^{*} \\
(0.0091)\end{array}$ & $\begin{array}{c}-0.0088 \\
(0.0077)\end{array}$ & $\begin{array}{c}0.0249^{* *} \\
(0.0134)\end{array}$ \\
\hline Intermediate professions & Ref. & Ref. & Ref. & Ref. \\
\hline Office worker & $\begin{array}{c}-0.0094 \\
(0.0076)\end{array}$ & $\begin{array}{l}-0.0043 \\
(0.0114)\end{array}$ & $\begin{array}{l}-0.0051 \\
(0.0108)\end{array}$ & $\begin{array}{c}0.0166 \\
(0.0174)\end{array}$ \\
\hline Blue-collar & $\begin{array}{c}0.0069 \\
(0.0069)\end{array}$ & $\begin{array}{c}0.0062 \\
(0.0099)\end{array}$ & $\begin{array}{l}0.0167^{*} \\
(0.0094)\end{array}$ & $\begin{array}{c}0.0271^{* *} \\
(0.0139)\end{array}$ \\
\hline $\begin{array}{l}\text { Characteristics of the spouse } \\
\text { Education }\end{array}$ & & & & \\
\hline No diploma & $\begin{array}{l}0.0173^{*} \\
(0.0103)\end{array}$ & $\begin{array}{c}0.0121 \\
(0.0130)\end{array}$ & $\begin{array}{c}0.0523^{* * *} \\
(0.0176)\end{array}$ & $\begin{array}{c}0.0955^{* * *} \\
(0.0269)\end{array}$ \\
\hline At most lower sec. edu. & $\begin{array}{c}0.0150 \\
(0.0095)\end{array}$ & $\begin{array}{c}0.0111 \\
(0.0131)\end{array}$ & $\begin{array}{c}0.0110 \\
(0.0188)\end{array}$ & $\begin{array}{c}0.0133 \\
(0.0225)\end{array}$ \\
\hline Vocational training & $\begin{array}{c}0.0064 \\
(0.0082)\end{array}$ & $\begin{array}{c}0.0064 \\
(0.0113)\end{array}$ & $\begin{array}{c}0.0116 \\
(0.0122)\end{array}$ & $\begin{array}{l}0.0255^{*} \\
(0.0161)\end{array}$ \\
\hline High school final diploma & Ref. & Ref. & Ref. & Ref. \\
\hline University diploma & $\begin{array}{c}0.0132 \\
(0.0080)\end{array}$ & $\begin{array}{c}0.0028 \\
(0.0109)\end{array}$ & $\begin{array}{c}0.0169 \\
(0.0154)\end{array}$ & $\begin{array}{c}0.0294 \\
(0.0195)\end{array}$ \\
\hline Nationality & & & & \\
\hline French born in France & Ref. & Ref. & Ref. & Ref. \\
\hline Foreign nationality & $\begin{array}{c}0.0160 \\
(0.0103)\end{array}$ & $\begin{array}{c}0.0183 \\
(0.0130)\end{array}$ & $\begin{array}{c}0.0154 \\
(0.0196)\end{array}$ & $\begin{array}{l}-0.0040 \\
(0.0131)\end{array}$ \\
\hline French born abroad & $\begin{array}{l}0.0147^{*} \\
(0.0089)\end{array}$ & $\begin{array}{c}0.0097 \\
(0.0110)\end{array}$ & $\begin{array}{c}0.0385 * * * \\
(0.0146)\end{array}$ & $\begin{array}{c}0.0424^{* *} \\
(0.0216)\end{array}$ \\
\hline $\begin{array}{l}\text { Urban unit characteristics } \\
\text { Unemployment rate }\end{array}$ & & & $\begin{array}{c}0.3810^{* * *} \\
(0.0075)\end{array}$ & $\begin{array}{c}0.3009 * * * \\
(0.0790)\end{array}$ \\
\hline Log-likelihood & $-2,339$ & -976 & $-1,571$ & -642 \\
\hline Pseudo-R $\mathrm{R}^{2}$ & 0.063 & 0.102 & 0.099 & 0.157 \\
\hline Number of observations & 10,473 & 4,849 & 6,299 & 2,897 \\
\hline
\end{tabular}

Notes: ${ }^{* * *},{ }^{* *}$ and ${ }^{*}$ denote significance at the $1 \%, 5 \%$ and $10 \%$ level respectively. Each equation also includes a constant. Figures in brackets give standard errors. For models estimated on the national sample (columns (3) and (4)), these are corrected for within urban unit dependencies.

Table 4: Marginal effects from simple probit models of unemployment 


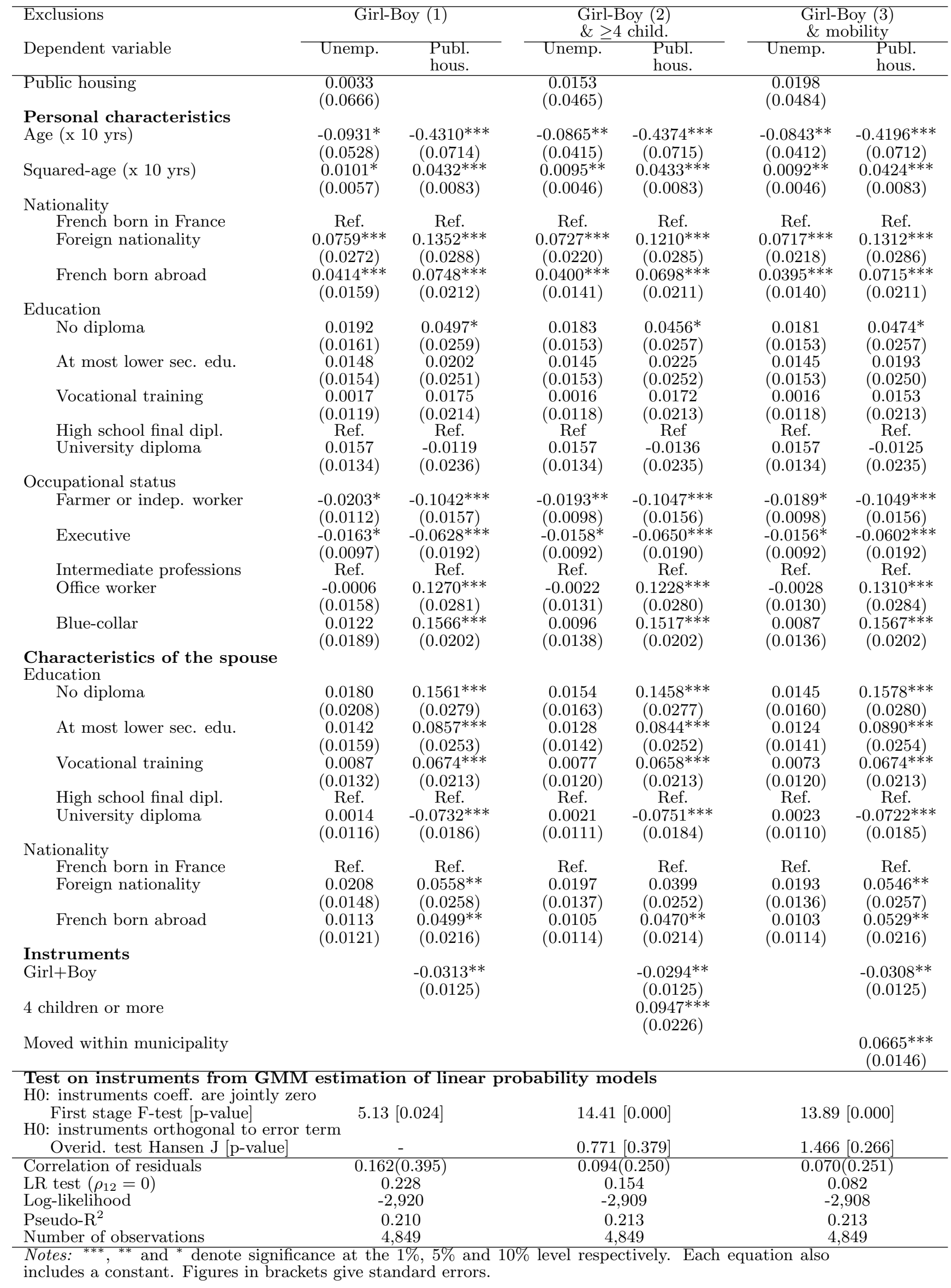

Table 5: Marginal effects from simultaneous probit models - Lyon sample (Population Census) 


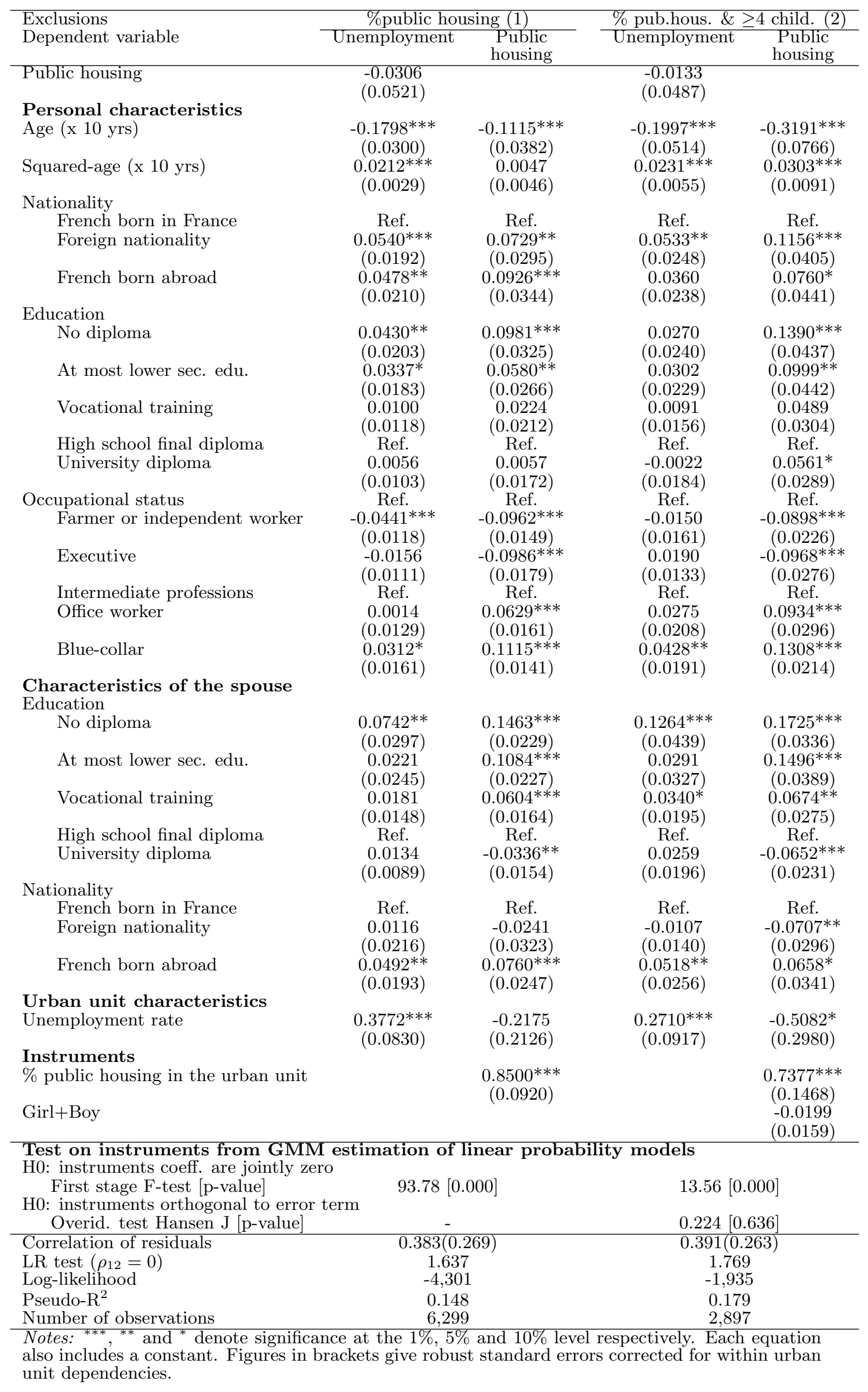

Table 6: Marginal effects from simultaneous probit models - National sample (Housing Survey) 


\begin{tabular}{|c|c|c|c|c|c|c|}
\hline Correlation of error terms & 0.00 & 0.05 & 0.10 & 0.15 & 0.20 & 0.25 \\
\hline $\begin{array}{l}\text { A: Lyon sample - all ho } \\
\quad(N=10,473)\end{array}$ & $\begin{array}{c}\text { seholds } \\
0.2674^{* * *} \\
(0.0483) \\
{[0.0351]}\end{array}$ & $\begin{array}{c}0.1904^{* * *} \\
(0.0482) \\
{[0.0232]}\end{array}$ & $\begin{array}{c}0.1048^{* *} \\
(0.0480) \\
{[0.0123]}\end{array}$ & $\begin{array}{c}0.0195 \\
(0.0478) \\
{[0.0022]}\end{array}$ & $\begin{array}{l}-0.0656 \\
(0.0475) \\
{[-0.0072]}\end{array}$ & $\begin{array}{c}-0.151 \\
(0.0471) \\
{[-0.0159]}\end{array}$ \\
\hline $\begin{array}{l}\text { B: Lyon sample - } \geq 2 \mathbf{2} \text { c } \\
(\mathrm{N}=4,849)\end{array}$ & $\begin{array}{c}\text { dren } \\
0.3093^{* * *} \\
(0.0730) \\
{[0.0338]}\end{array}$ & $\begin{array}{c}0.2238^{* * *} \\
(0.0728) \\
{[0.0235]}\end{array}$ & $\begin{array}{c}0.1384^{*} \\
(0.0726) \\
{[0.0140]}\end{array}$ & $\begin{array}{c}0.0531 \\
(0.0722) \\
{[0.0052]}\end{array}$ & $\begin{array}{c}-0.0324 \\
(0.0717) \\
{[-0.0031]}\end{array}$ & $\begin{array}{c}-0.1179^{*} \\
(0.0711) \\
{[-0.0109]}\end{array}$ \\
\hline $\begin{array}{l}\text { C: National sample - al } \\
\quad(N=6,299)\end{array}$ & $\begin{array}{c}\text { aouseholds } \\
0.3823^{* * *} \\
(0.0507) \\
{[0.0556]}\end{array}$ & $\begin{array}{c}02971 * * * \\
(0.0504) \\
{[0.0417]}\end{array}$ & $\begin{array}{c}0.2121^{* * *} \\
(0.0500) \\
{[0.0288]}\end{array}$ & $\begin{array}{c}0.1271^{* *} \\
(0.0496) \\
{[0.0167]}\end{array}$ & $\begin{array}{c}0.0422 \\
(0.0491) \\
{[0.0054]}\end{array}$ & $\begin{array}{c}-0.0427 \\
(0.0486) \\
{[-0.0053]}\end{array}$ \\
\hline $\begin{array}{l}\text { D: National sample - } \\
\quad(\mathrm{N}=2,897)\end{array}$ & $\begin{array}{c}\text { children } \\
0.5383^{* * *} \\
(0.0767) \\
{[0.0696]}\end{array}$ & $\begin{array}{c}0.4533^{* * *} \\
(0.0765) \\
{[0.0565]}\end{array}$ & $\begin{array}{c}0.3680 * * * \\
(0.0761) \\
{[0.0443]}\end{array}$ & $\begin{array}{c}0.2826 * * * \\
(0.0756) \\
0.0329]\end{array}$ & $\begin{array}{c}0.1969 * * * \\
(0.0749) \\
{[0.0223]}\end{array}$ & $\begin{array}{c}0.1108 \\
(0.0742) \\
{[0.012]}\end{array}$ \\
\hline
\end{tabular}

Notes: ${ }^{* * *},{ }^{* *}$ and ${ }^{*}$ denote significance at the $1 \%, 5 \%$ and $10 \%$ level respectively.

Figures in parentheses give standard errors, corrected for within-urban-unit dependencies for models in panel C and D. Figures in brackets give marginal effects.

All models also include: a constant, age, squared-age, nationality, diploma, occupational status, spouse's diploma and nationality. Models in panel C and D also include the unemployment rate in the urban unit.

Table 7: Public housing estimates from simultaneous probit models with different constraints on the correlation between error terms 